\title{
Correlation between Maternal Hemoglobin Level and Birth Weight
}

\author{
Syifa Fauziyah Safithri, ${ }^{1}$ Nia Kania, ${ }^{2}$ Aly Diana ${ }^{3}$ \\ ${ }^{1}$ Faculty of Medicine Universitas Padjadjaran, ${ }^{2}$ Department of Biomedical Sciences Faculty of \\ Medicine Universitas Padjadjaran, ${ }^{3}$ Department of Public Health Faculty of Medicine \\ Universitas Padjadjaran
}

\section{Abstract}

Background: Pregnant women are susceptible to have anemia, marked by hemoglobin level <11gr/ $\mathrm{dL}$. Maternal hemoglobin levels may influence the nutritional transfer, oxygenation, and uteroplacental circulation of the babies which may affect the infant's birth weight. This study aimed to explore the correlation between hemoglobin level and birth weight in pregnant women in rural area in Bandung.

Methods: This cross-sectional study was conducted from August to September 2014, recruiting all pregnant women registered in a hospital in a rural areas Bandung. Hemoglobin level was obtained from the medical records and analyzed to correlate with birth weight (Pearson correlation).

Results: In total, there were 95 pregnant women included. The mean of maternal hemoglobin level was $11.6 \pm 1.2 \mathrm{gr} / \mathrm{dL}$ and birth weight was $2.927 \pm 398 \mathrm{gram}$. The proportion of maternal anemia and low birth weights were $30.5 \%$ and $15.8 \%$, respectively. Pearson correlation test showed $r=-0.093$ and $p=0.369$ which was not significant.

Conclusions: There was no correlation between maternal hemoglobin level and birth weight. Other factors for low maternal hemoglobin need to be further explored.

Keywords: Birth weight, hemoglobin, maternal

\section{Introduction}

Pregnant women are susceptible to have anemia. There is $37.1 \%$ of pregnant women with anemia, as reported in data of Basic Health Research (Riset Kesehatan Dasar, Riskesdas) Indonesia 2013. ${ }^{1}$ During pregnancy, blood volume is increased due to higher plasma volume and erythrocyte numbers. The plasma increase is higher than hemoglobin, leading to a lower hemoglobin concentration. Low hemoglobin concentration in pregnant women below $11 \mathrm{~g} / \mathrm{dL}$ is designated as anemia of pregnant women. ${ }^{2}$ One of the effects of anemia in pregnant women is a delivered baby with low birth weight. ${ }^{2}$ This may be to disturbance to nutrition, oxygenation and uteroplacental

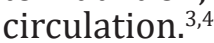

According to the World Health Organization (WHO), low birth weight is designated when infant weight is less than 2500 grams (5.5 pounds) at birth. ${ }^{5}$ Infant with low birth weight may have a higher risk of mortality and morbidity, such as the occurrence of growth retardation, delayed cognitive development and the risk of chronic diseases during lifetime. ${ }^{3,5}$ Previous study in India among pregnant women in their third trimester has shown that anemia during pregnancy has a negative effect on the infant birth weight. ${ }^{6}$

This study aimed to explore the correlation between maternal hemoglobin level and birth weight in a rural area in Bandung.

\section{Methods}

The study design was a cross-sectional study, conducted from August to September 2014 in a rural area in Bandung. A total sample of 95 pregnant women was included from data obtained from medical records of pregnant women from January 2011 until May 2014. The inclusion criteria was pregnant women

Correspondence: Syifa Fauziyah Safithri, Faculty of Medicine Universitas Padjadjaran, , Jalan Raya Bandung Sumedang Km. 21 Jatinangor, Sumedang Indonesia, Email: syifafsafithri@gmail.com 
Table 1 The Baseline Characteristics of Pregnant Women

\begin{tabular}{lcc}
\hline \multicolumn{1}{c}{ Characteristics } & $\mathbf{n = 9 5}$ & $\mathbf{\%}$ \\
\hline Parity & 39 & 41.1 \\
0 & 42 & 44.2 \\
1 & 10 & 10.5 \\
2 & 4 & 4.2 \\
3 & & \\
Educational Level & 5 & 5.3 \\
Elementary School & 21 & 22.1 \\
Junior High School & 43 & 45.3 \\
Senior High School & 26 & 27.3 \\
High Education & & \\
Occupation & 37 & 38.9 \\
Working & 58 & 61.1 \\
Housewife & &
\end{tabular}

aged 20-35 years old whereas the exclusion criteria was pregnant women with high parity (more than 4 previous live births), history of abortion, multiple gestation, premature birth, a baby with congenital abnormalities, history of chronic diseases (hypertension, diabetes, asthma, heart disease, tuberculosis, and renal failure) and bleeding during pregnancy (placental abruption and placenta previa).

Data of third-trimester maternal hemoglobin level and birth weight were obtained from the medical record of pregnant women who gave birth at the AMC Hospital Bandung after getting ethical approval from the Ethics Committee of the AMC Hospital Bandung.

Data were collected and analyzed by univariate to find the proportion of each variable, and by bivariate to find the correlation between two variable using
Pearson correlation test, with a significant value of $p<0.05$ using statistical software (SPSS).

\section{Results}

Of 95 pregnant women included, 44.2\% had ever given birth for once (1 parity). The majority were graduated from senior high school (45.3\%), and housewife (61.1\%) as shown in Table 1.

The proportion of maternal anemia and low birth weight were $30.5 \%$ and $15.8 \%$, respectively (Table 2). The mean of maternal hemoglobin level was $11.6 \pm 1.2 \mathrm{gr} / \mathrm{dl}$ and birth weight was $2927 \pm 398$ gram.

The linear test was used after normality test. It showed $p$-value $=0.783 \quad(p>0.05)$, this result indicates that there was a linear

Table 2 Hemoglobin Maternal Level and Infant Birth Weight

\begin{tabular}{lcc}
\hline \multicolumn{1}{c}{ Characteristics } & $\mathbf{n = 9 5}$ & $\mathbf{\%}$ \\
\hline Hemoglobin Level & & \\
$<11$ gr/dL & 29 & 30.5 \\
$11-13$ gr/dL & 58 & 61.1 \\
$>13$ gr/dL & 8 & 8.4 \\
Infant Birth Weight & & \\
$<2500$ gram & 15 & 15.8 \\
$\geq 2500$ gram & 80 & 84.2 \\
\hline
\end{tabular}




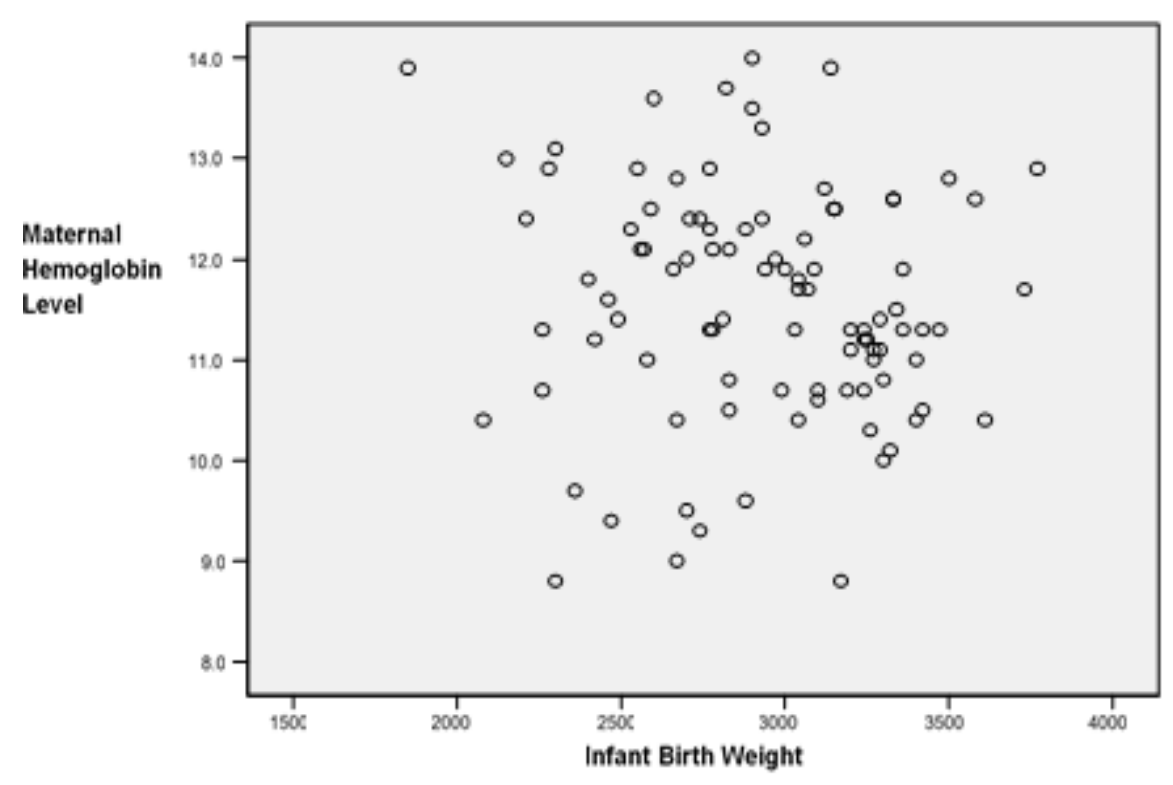

\section{Figure 1 The Linear Relationship between Maternal Hemoglobin Level and Infant Birth Weight}

relationship between maternal hemoglobin level and infant birth weight, as shown in Figure 1. Furthermore, the Pearson correlation test was used to see how close the relationship between the two variables.

Pearson correlation test showed that the value of the Pearson correlation coefficient ( $\mathrm{r}$ ) was -0.093 , indicating a very weak correlation with a negative correlation and value of $p=0.369 \quad(p>0.05)$, showing no significant relationship between maternal hemoglobin level and infant birth weight.

\section{Discussion}

This study has shown that $30.5 \%$ of pregnant women are anemic, and this is slightly lower than the national percentage of $37.1 \%{ }^{1}$ The characteristics of the respondents are different compared to the national characteristic in general. Furthermore, these pregnant women have had a normal delivery. In this study, the results show no significant correlation between hemoglobin level of pregnant women with birth weight $(p=0.369)$, likewise, in a previous study in other parts of Indonesia in West Sumatra, also has shown no significant correlation between maternal hemoglobin level in the third trimester and infant birth weight. ${ }^{7}$ Many confounding factors cannot be controlled, such as maternal age, parity, nutritional status, chronic disease during pregnancy, genetic factors, characteristics of antenatal care, maternal smoking habits, and socioeconomic condition. ${ }^{7}$ These factors may have been taken into consideration. In another study conducted in Africa has shown a similar result that there is no significant relationship between maternal hemoglobin levels and birth weight. ${ }^{8}$

There evidence that various factors may influence condition of anemia and birth weight such as low maternal nutrition before and during pregnancy, age less than 20 years old during pregnancy, abortion history, a history of having a baby with low birth weight, parity $\geq 4$ times, women with chronic illness during pregnancy, premature birth, the mother who had multiple gestation, pregnant women that do not consume or low consume of iron tablets, lack of antenatal visits, low maternal education level, and low socioeconomic condition. ${ }^{9-12}$ In our study, most of these factors have been controlled by exclusion criteria, however, several factors are not examined because of the incomplete data in the medical records. Furthermore, several factors that affect birth weight were not studied, such as maternal nutrition before and during pregnancy, intake of iron tablets, antenatal visits during pregnancy, and socioeconomic condition, whereas it may become a confounding factor in this study. $7,9-13$

of note, maternal nutritional intake 
before and during pregnancy can affect fetal development. Poor nutrition in the mother before and during pregnancy can lead to a lack of nutrients that are transmitted through the placenta to the baby. ${ }^{3}$ Inadequate intake of iron tablets during pregnancy and the lack of antenatal care visits may increase the risk of low birth weight of the baby. ${ }^{9}$ The intake of iron tablets during pregnancy helps increasing overall maternal nutrition so it may increase the birth weight of the baby. ${ }^{9}$ In antenatal visits, the risk of low birth weight can be reduced because antenatal visits can improve the mother's diet during pregnancy, monitor and assist the mother in weight gain during pregnancy. ${ }^{9}$ Socioeconomic conditions have an important role for pregnant women because it affects maternal nutrition before and during pregnancy. ${ }^{7,12}$

Regardless our finding with no association between low hemoglobin during pregnancy and low birth weight, some previous studies have shown otherwise resulting that low hemoglobin level during pregnancy is associated with low birth weight. ${ }^{14,15}$ Interestingly, when the severity of anemia in the third trimester of pregnancy is decreased, the average birth weight is increased. ${ }^{6}$

Limitations of this study were that not all influencing factors can be controlled, such as maternal nutrition before and during pregnancy, intake of iron tablets, antenatal visits during pregnancy, and socioeconomic condition. Further study needs to include all of these factors, by doing primary data collection with a prospectively cohort study method and assessing hemoglobin level from first until the third trimester of pregnancy. As for secondary data, in order to control the factors that may affect the results, a good medical record is encouraged, such as data of third trimester hemoglobin level, maternal history of the ANC, and keeping medical records in good place, to be used for any later study, and to provide complete information.

To conclude, our study shows that there is no correlation between hemoglobin levels of pregnant women with birth weight. Other factors for low maternal hemoglobin need to be further explored.

\section{References}

1. Badan Penelitian dan Pengembangan Kesehatan. Riset Kesehatan Dasar 2013. Jakarta: Kementerian Kesehatan RI; 2013.

2. Lee AI, Okam MM. Anemia in pregnancy. Hematol Oncol Clin N Am. 2011;25(2):24159.
3. Muthayya S. Maternal nutrition and low birth weight. Indian J Med Res. 2009;130(5):600-8.

4. Cunningham FG, Gant NF, Leveno KJ, Gilstrap LC, Hauth JC, Wenstrom KD. Williams Obstetrics. 23rded. New York: The McGraw-Hill Companies; 2010.

5. United Nations Children's Fund and World Health Organization. Low birthweight:country, regional and global estimates. New York: UNICEF; 2004.

6. Madaan G, Bhardwaj AK, Narang S, Sharma P. Effects of third trimester maternal hemoglobin upon newborn anthropometry. J Nepal Paediatr Soc. 2013;33(3):186-9.

7. Setiawan A, Lipoeto NI, Izzah AZ. Hubungan kadar hemoglobin ibu hamil trimester III dengan berat bayi lahir di Kota Pariaman. Jurnal Kesehatan Andalas. 2013;2(1):347.

8. Demmouche A, Lazrag A, Moulessehoul S. Prevalence of anemia in pregnant women during the last trimester : consequense for birth weight. Eur Rev Med Pharmacol Sci. 2011;15(4):436-45.

9. Khanal V, Zhao Y, Sauer K. Role of antenatal care and iron supplementation during pregnancy in preventing low birth weight in Nepal:comparison of national surveys 2006 and 2011. Arch Public Health. 2014;72(1):4-13.

10. Kumar SG, Kumar HH, Jayaram S, Kotian M. Determinants of low birth weight: a case control study in a district hospital in Karnataka. Indian J Pediatr. 2010;77(1):87-9.

11. Nobile CG, Raffaele G, Altomare C, Pavia M. Influence of maternal and social factors as predictors of low birth weight in Italy. BMC Public Health. 2007;7(1):192-200.

12. Matin A, Azimul S, Matiur A, Shamianaz S, Shabnam J,Islam T.Maternal socioeconomic and nutritional determinants of low birth weight in urban area of Bangladesh. J Dhaka Med Coll. 2008;17(2):83-7.

13. Dasgupta A, Basu R. Determinants of low birth weight in a Block of Hooghly, West Bengal. Int J Biol Med Res. 2011;2(4):83842.

14. Francis S, Nayak S. Maternal haemoglobin level and its association with pregnancy outcome among mothers. NUJHS. 2013;3(3):96-100.

15. Ahmad MO, Kalsoom U, Sughra U, Hadi U, Imran M. Effect of maternal anaemia on birth weight. J Ayub Med Coll Abbottabad. 2011;23(1):77-9. 